\title{
TEKNIK PERANGKINGAN META-SEARCH ENGINE
}

\author{
Diyah Puspitaningrum \\ Program Studi Teknik Infomatika, Fakultas Teknik, Universitas Bengkulu. \\ Jl. WR. Supratman Kandang Limun Bengkulu 38371A INDONESIA \\ (telp: 0736-341022; fax: 0736-341022) \\ diyah@cs.uu.nl
}

\begin{abstract}
Abstrak: Meta-search engine mengorganisasikan penyatuan hasil dari berbagai search engine dengan tujuan untuk meningkatkan presisi hasil pencarian dokumen web. Pada survei teknik perangkingan metasearch engine ini akan didiskusikan isu-isu pra-pemrosesan, rangking, dan berbagai teknik penggabungan hasil pencarian dari search engine yang berbeda-beda (multi-kombinasi). Isu-isu implementasi penggabungan 2 search engine dan 3 search engine juga menjadi sorotan. Pada makalah ini juga dibahas arahan penelitian di masa yang akan datang.

Kata kunci: Meta-search engine, Merging multiple web document, Web document ranking, IR.
\end{abstract}

\begin{abstract}
Meta-search engines organize merging of different search engine results with aim to improve precision of web documents' search results. In this survey, we discuss the issues that must be addressed in the ranking of meta-search engines, including preprocessing (queries selection, post-query processing, and judgments), the ranking itself (search engines rank order, overlapping test, precision ratio), and different merging policies. We emphasize the role played by multiple combination. We highlight the implementation issues of performance of merging two and three engines consecutively. Some directions for future research are finally presented.
\end{abstract}

Keywords: Meta-search engines, Merging multiple web document, Web document ranking, IR.

\section{PENDAHULUAN}

Meta-search engine adalah sistem yang mendukung penyatuan akses terhadap beberapa search engine yang ada. Meta-search engine ini menerima input berupa query dari user yang kemudian hasil pencarian dari berbagai search engine digabungkan. Hasil yang diperoleh kemudian perlu dirangkingkan untuk membantu pencarian individual.

Web merupakan sumber informasi yang sangat besar, dan setiap search engine secara individual mungkin hanya mencakup sebagian kecil dari informasi tersebut, dan jika user hanya menggunakan satu search engine maka ada kemungkinan bahwa user tidak pernah melihat halaman-halaman web lain yang tidak dicakup oleh seach engine tersebut tetapi muncul pada search engine-search engine lainnya. Dengan adanya meta-search engine hasil-hasil dari berbagai search engine digabungkan sehingga presisi pencarian dapat ditingkatkan.

\section{Tujuan Perangkingan Meta-Search Engine}

Masalah penyatuan dalam IR adalah masalah yang sulit karena search engine yang bermacammacam menggunakan algoritma rangking yang juga bermacam-macam berdasarkan statisik corpus masing-masing. Dari penggabungan hasil pencarian dari berbagai search engine diingini untuk menghasilkan satu fusi rangking tunggal mengatasi semuanya.

\section{LANDASAN TEORI}

A. Overview Teknik Meta-Search Engine

1) Prinsip-Prinsip Pemilihan Query: Query adalah alat utama untuk menerjemahkan 
kebutuhan informasi user ke dalam sebuah format yang dapat dimengerti oleh sistem IR dengan kata kunci-kata kunci (atau terms) sebagai pembentuk dasar sebuah query.

Jansen dkk [1] menganalisis file transaksi dari search engine Excite yang berisikan 51.473 query yang dikeluarkan oleh 18.113 user untuk mengidentifikasi query berbasis panjang (yaitu banyaknya terms), kemudian struktur (penggunaan operator-operator Boolean dan modifier-modifier lainnya), serta analisis kegagalan. Jansen dkk mengidentifikasi bahwa query-query web umumnya pendek karena 62\% dari semua query yang dianalisis berisikan satu atau 2 term, kurang dari 4\% memiliki lebih dari 6 term. Hal ini kurang dari rata-rata jumlah pencarian term yang digunakan dalam pencarian regular sistem IR yang berkisar antara 7 sampai 15 term.

Untuk mengembangkan framework penggabungan hasil-hasil pencarian berbagai search engine sebaiknya memenuhi aturan berikut [2]:

- $\quad$ Tidak ada query term tunggal yang digunakan. Rata-rata term query web terdiri atas 2 term.

- Hanya query-query subjek yang disertakan dan tidak termasuk query-query item yang diketahui yang mencari informasi mengenai orang tertentu, institusi tertentu, dan atau produk yang diberikan, yang bisa lansung memberikan kepuasan karena item ditemukan pada list bagian atas.

- Query sebaiknya berbentuk frase kata benda. Ini pola yang umum dalam pencarian web.

- Semua variasi yang mungkin dari term-term query harus diindikasikan untuk mengembangkan strategi pencarian yang handal dan mengeksekusi term-term yang paling tepat.
Dalam pemilihan topik bisa berdasarkan real user queries yaitu berdasarkan kebutuhan informasi user, atau artificial queries yaitu pembangkitan query yang hanya berdasarkan topik tertentu saja yang terbatas, atau bisa menggunakan TREC queries menggunakan koleksi TREC yang sudah tersedia beserta penilaian relevansinya.

Dalam menjalankan query pendekatan terbaik untuk meta-search engine adalah membangun sebuah interface dimana query bisa diarahkan ke semua target search engine pada waktu yang bersamaan. Pendekatan ini telah diadopsi oleh banyak meta-search engine [3]]. Dong [4] juga menguji 30 query umum dan menyatakan 30 query adalah jumlah yang tepat untuk menguji kinerja search engine web.

2) Post-Processing: Begitu query dieksekusi oleh beberapa search engine, 20 item pertama dan jumlah total item yang ditarik dari setiap search engine disimpan dalam bentuk file teks. Spreadsheet kemudian digunakan untuk mengumpulkan 10 item pertama teratas dari 3 search engine dalam sebuah format teks. Spreadsheet ini menyimpan 30 item dan record untuk setiap item yaitu urutan rangking halaman web pada search engine aslinya, sebuah bilangan acak yang dibangkitkan dari tabel acak, judul halaman web, dan URL web. Bilangan acak untuk menentukan penilaian yang adil karena tidak diketahui dari search engine mana halaman web yang dinilai berasal. Spreadsheet kemudian diproses dengan tujuan:

1. Mendeteksi dan menghapus internal dan eksternal overlap

2. Mengacak urutan ranking dari item yang ditarik 
3. Memproduksi sebuah indeks file HTML termasuk di dalamnya: judul item pada halaman asli search engine yang asli.

3) Penilaian Relevansi (Relevance Judgements): Skala relevansi dalam lingkungan web adalah seperti diindikasikan oleh Sormunen (2002), yaitu sama seperti yang digunakan pada track Web TREC (TREC-7 dan 8) sebagai berikut:

4: Sangat relevan: Dokumen mendiskusikan tema dari topik secara mendalam. Dalam menghadapi berbagai topik, semua atau kebanyakan sub tema tercakup. Contohnya: beberapa paragraph teks, paling sedikit 4 kalimat atau fakta.

3: Relevan: Dokumen berisi informasi lebih mengenai deskripsi topik tetapi tidak mendalam. Contohnya: 1 paragraf tulisan, 2-3 kalimat atau fakta.

2: Setengah relevan: Hanya menunjuk langsung ke topik, tidak berisi informasi lebih mengenai deskripsi topik. Contohnya: satu kalimat atau fakta seperti definisi topik atau deskripsi.

1: Tidak relevan: Dokumen tidak berisi informasi mengenai topik tetapi dokumen menyebutkan term query.

0: Sangat tidak relevan: Dokumen tidak berisi informasi mengenai topik sama sekali

\section{METODOLOGI}

A. Overview Teknik Perangkingan Meta-Search Engine

1) Urutan Rangking Search Engine: Untuk menentukan urutan optimal rangking dari search engine tertentu, perlu dibandingkan total jumlah item yang ditarik per query dibandingkan dengan search engine-search engine lainnya dan rasio presisi dari setiap search engine untuk menguji efek dari ukuran database pada jumlah dokumen yang ditarik per query dan pada presisi dari 10 dokumen pertama yang ditarik oleh setiap search engine. Pengujian dilakukan berdasarkan pada kinerja umum dan atas panjang query yang berbeda-beda.

Sebagai contoh (Mohamed, 2004) melakukan query ke 3 search engine total sebanyak 40 query dengan masing-masing panjang query 2 term sebanyak 20 query dan 3 term sebanyak 20 query.

Tabel 1 menunjukkan rata-rata banyaknya dokumen yang ditarik untuk setiap search engine per panjang query

\begin{tabular}{|c|c|c|c|}
\hline Search Engine & Mean & $\begin{array}{c}\text { Standar } \\
\text { Deviasi }\end{array}$ & $\mathbf{N}$ \\
\hline Google term=2 & 14882.55 & 23029.6045 & 20 \\
\hline Google term=3 & 9907.4 & 32147.584 & 20 \\
\hline $\begin{array}{c}\text { AltaVista } \\
\text { term=2 }\end{array}$ & 4703.2 & 7776.75565 & 20 \\
\hline $\begin{array}{c}\text { AltaVista term } \\
=3\end{array}$ & 1686.35 & 3527.91228 & 20 \\
\hline Fast term =2 & 11678.9 & 22345.1892 & 20 \\
\hline Fast term =3 & 3988.75 & 13508.4384 & 20 \\
\hline
\end{tabular}

Tabel 1 tersebut menunjukkan bahwa Google berkinerja lebih baik daripada AltaVista dan Fast dalam hal jumlah dokumen yang ditarik per query untuk panjang query yang berbeda.

Untuk ketiga search engine banyaknya dokumen yang ditarik secara positif berhubungan dengan ukuran database. 


\begin{tabular}{|c|c|c|c|}
\hline Two Terms & Google & AltaVista & Fast \\
\hline 1 & 669 & 351 & 357 \\
\hline 2 & 947 & 486 & 459 \\
\hline 3 & 121 & 78 & 75 \\
\hline 4 & 150 & 46 & 72 \\
\hline 5 & 8 & 9 & 10 \\
\hline 6 & 81500 & 27026 & 83029 \\
\hline 7 & 28400 & 9638 & 15139 \\
\hline 8 & 47700 & 24440 & 59225 \\
\hline 9 & 13200 & 5770 & 5453 \\
\hline 10 & 11100 & 1350 & 1407 \\
\hline 11 & 1720 & 181 & 155 \\
\hline 12 & 2980 & 1705 & 1975 \\
\hline 13 & 8410 & 3645 & 14510 \\
\hline 14 & 9300 & 513 & 7491 \\
\hline 15 & 21100 & 8763 & 35392 \\
\hline 16 & 1540 & 1119 & 2098 \\
\hline 17 & 1920 & 746 & 183 \\
\hline 18 & 4380 & 1898 & 1780 \\
\hline 19 & 62000 & 6053 & 4616 \\
\hline 20 & 506 & 247 & 152 \\
\hline A verage & 14882.55 & 4703.2 & 11678.9 \\
\hline $\begin{array}{l}\text { Three } \\
\text { Term s }\end{array}$ & 1310 & 855 & 904 \\
\hline 21 & 33 & 12 & 10 \\
\hline 22 & 31 & 15 & 21 \\
\hline 23 & 185 & 116 & 63 \\
\hline 24 & 2850 & 1402 & 1299 \\
\hline 25 & 67 & 35 & 42 \\
\hline 26 & 943 & 514 & 1354 \\
\hline 27 & 47 & 24 & 18 \\
\hline 28 & 432 & 230 & 231 \\
\hline 29 & 71 & 37 & 63 \\
\hline 30 & 3310 & 1566 & 1761 \\
\hline 31 & 2400 & 1047 & 937 \\
\hline 32 & 32600 & 14042 & 60493 \\
\hline 33 & 143000 & 8746 & 10755 \\
\hline 34 & 63 & 39 & 27 \\
\hline 35 & 89 & 23 & 75 \\
\hline 36 & 57 & 20 & 24 \\
\hline 37 & 7160 & 3346 & 49 \\
\hline 38 & 2790 & 1344 & 1304 \\
\hline 39 & 710 & 314 & 345 \\
\hline 40 & 9907.4 & 1686.35 & 3988.75 \\
\hline $\begin{array}{c}\text { Whole Set } \\
\text { Average }\end{array}$ & 12394.98 & 3194.775 & 7833.825 \\
\hline
\end{tabular}

Atau digambarkan ke dalam chart:

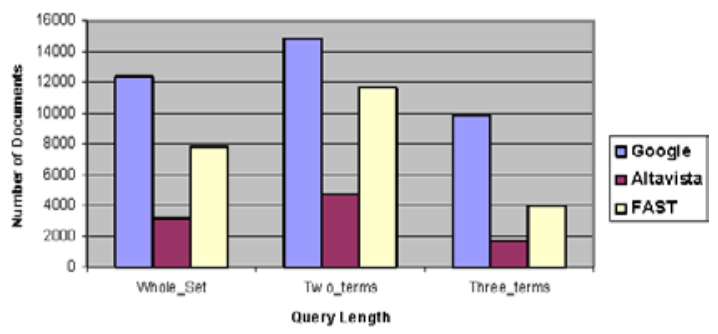

Gambar 1. Banyaknya dokumen yang ditarik [2]

yang juga membenarkan asumsi bahwa secara umum query yang kompleks menarik lebih sedikit halaman daripada query yang sederhana.
2) Uji Overlapping: Terdapat sejumlah overlapping pada hasil yang ditarik dari ketiga search engine (lihat Appendiks 1). Persentase dokumen yang overlap ditunjukkan pada Gambar 2.

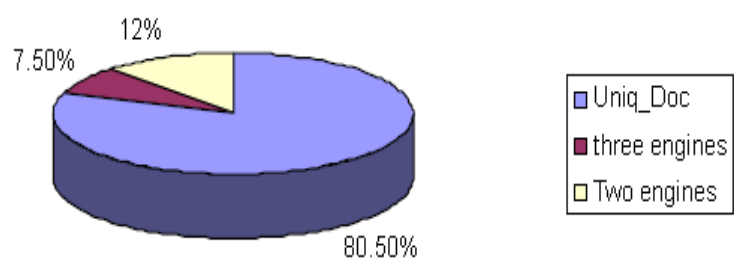

Gambar 2. Persentase dokumen yang overlap [2]

Studi lain yang meneliti tentang overlapping antara 2 search engine berkisar antara 10 sampai 15\% [4]. Proporsi dokumen overlapping meningkat ketika derajat kompleksitas query menurun.

3) Rasio Presisi: Search engine menarik ribuan dokumen untuk mayoritas query. Presisi menjadi sangat penting tetapi recall menjadi tidak terlalu penting [ㄷ].

1. Rasio Presisi Search Engine Individual

Rasio ini mengukur tingkat presisi 10 item pertama. Contoh untuk search engine Google(g):

$$
A P R_{g}=\frac{\sum_{Q=1}^{N} P}{N}
$$

APR adalah rasio presisi rata-rata (average precision ratio) dimana jumlah presisi (P) untuk setiap query (Q) dibagi dengan banyaknya query (N). Pada kasus [2] diambil query $\mathrm{Q}=1, \ldots, 40$.

\section{Presisi Hasil Gabungan}

Presisi gabungan antara 2 search engine dan 3 search engine juga diukur. Sebagai contoh: kombinasi antara Google(g) dan AltaVista(a): 


$$
A P R_{g a}=\frac{\sum_{Q=1}^{N} P(g a)}{N}
$$

Dan kombinasi 3 search engine: Google (g), AltaVista(a) dan Fast(f):

$$
A P R_{\text {gaf }}=\frac{\sum_{Q=1}^{N} P(\text { gaf })}{N}
$$

3. Presisi Pada 11 Point Recall Values $11 P$ cutoff/recall values:

$$
P 11=\frac{\sum \text { precisionrelevant, } Q}{N}
$$

dimana $\mathrm{N}=40$ query.

Sebagai contoh: jika sebuah sistem search engine menarik hanya 4 dokumen yang relevan pada urutan rank 2, 3, 5, dan 7 maka pada recall point 0.3 presisi adalah $2 / 3=0.667$ karena $\mathrm{di}$ antara top 3 dokumen hanya 2 dokumen yang relevan. Sebagai contoh lagi, jika presisi 0.30 cut off recall adalah 0.5, 0.37, dan 0.40 untuk Google, AltaVista, dan Fast, maka rata-rata presisi adalah $(0.5+0.37+0.40) / 3=0.423$. Semua kombinasi yang mungkin dibandingkan pada $11 P$ cutoff values. Contoh kombinasi lainnya maksudnya seperti : recall point 0.60 artinya dicari berapa banyak dokumen yang relevan dalam 6 dokumen pertama; recall point 0.90 artinya dicari berapa banyak dokumen yang relevan dalam 9 dokumen pertama.

Tabel 2. Search Engine P11 atas 40 query

\begin{tabular}{|c|c|c|c|c|}
\hline Recall & Google & Altavista & FAST & Average \\
\hline 0 & 0.89 & 0.7275 & 0.7275 & 0.781667 \\
\hline 0.1 & 0.796668 & 0.705 & 0.655 & 0.718889 \\
\hline 0.2 & 0.794995 & 0.682495 & 0.644995 & 0.707495 \\
\hline 0.3 & 0.788125 & 0.663125 & 0.594375 & 0.681875 \\
\hline 0.4 & 0.755 & 0.6525 & 0.5875 & 0.665 \\
\hline 0.5 & 0.737918 & 0.646255 & 0.575003 & 0.653058 \\
\hline 0.6 & 0.730003 & 0.635355 & 0.544244 & 0.636534 \\
\hline 0.7 & 0.704688 & 0.609063 & 0.536875 & 0.616875 \\
\hline 0.8 & 0.6907 & 0.608613 & 0.52611 & 0.608474 \\
\hline 0.9 & 0.6825 & 0.60375 & 0.50625 & 0.5975 \\
\hline 0.1 & 0.6825 & 0.60375 & 0.50625 & 0.5975 \\
\hline
\end{tabular}

Gambar 3 menunjukkan Google muncul sebagai pemenang diikuti oleh AltaVista dan Fast. Google selalu berkinerja di atas rata-rata. AltaVista berkinerja di bawah rata-rata pada 5 kasus pertama dan selebihnya sama dengan rata-rata. Fast selalu di bawah rata-rata.

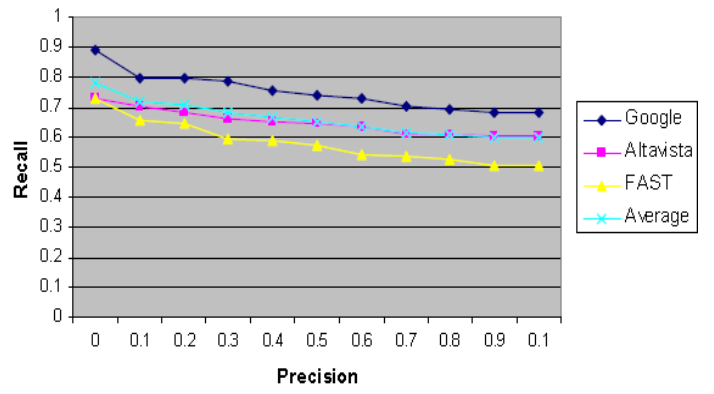

Gambar 3. Presisi pada 11 point cutoff recall

11 cutoff values dibagi ke dalam 3 range recall: 1) kisaran presisi tinggi yaitu dari 0 ke 0.2; 2) kisaran recall sedang yaitu dari 0.2 sampai 0.8 ; 3) kisaran recall tinggi yaitu dari 0.8 ke 1 . Google tetap sebagai pemenang.

4) Teknik Penggabungan Hasil-Hasil Search Engine:

A. Kinerja Dari Multi Kombinasi

Terdapat 3 fungsi yang masing-masing digunakan untuk menggabungkan hasil GoogleAltaVista, Google-Fast, AltaVista-Fast, yaitu: rank similarity, global similarity, dan interleave. Tujuannya mencari kombinasi terbaik dan metode terbaik dari penggabungan hasil pencarian.

\section{Rank Similarity}

Fungsi Rank similarity diajukan oleh Lee (1997). Fungsi ini mengasumsikan bahwa sebuah dokumen (D1) yang berangking pada posisi R dari himpunan penarikan data yang lebih besar daripada dokumen (D2) yang berangking pada posisi yang sama dari himpunan yang lebih kecil, ketika digabung kedua daftar tersebut D1 diproses lebih dulu dari D2. 


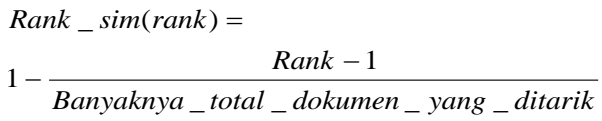

Sebagai contoh sebuah penarikan individual menarik 1000 dokumen paling atas. Diberikan sebuah dokumen yang berada pada rangking 10 dengan nilai similaritas $1-((10-1) / 1000)=0.991$. Sebuah sistem lain menarik 2000 dokumen. Dokumen yang berada pada rangking 10 memiliki nilai similaritas $1-((10-1) / 2000)=0.996$. Jadi meskipun berangking sama, dokumen yang berasal dari dataset yang lebih besar harus diletakkan lebih dulu.

\section{Global Similarity}

Fungsi Global Similarity Function (GSF) dikembangkan oleh Yuwono dan Lee (1996) dikombinasikan dengan fungsi penyatuan CombSUM (Fox and Show, 1995). Rumus GSF:

$$
\mathbf{g}=\mathbf{1}-(\mathbf{r}-\mathbf{1}) * \mathbf{F i}
$$

dimana $r$ adalah rangking dokumen dan Fi didefinisikan sebagai:

$$
\mathbf{F i}=\left(\mathbf{r}_{\min }\right) /\left(\boldsymbol{m} * \mathbf{r}_{i}\right)
$$

dimana $\mathrm{r}_{\min }$ adalah minimum rangking database, $\mathrm{r}_{i}$ adalah rangking database, dan $m$ adalah banyaknya dokumen yang diinginkan dari semua database yang dicari.

CombSUM adalah untuk penanganan dokumen overlap, yaitu, penjumlahan skor kesamaan global yang ditunjukkan melalui penarikan individual. Sebagai contoh jika terdapat 3 dokumen yang ditarik dimana dokumen pertama ditarik dari ketiga search engine, dokumen ke dua ditarik dari dua search engine, dan dokumen ketiga hanya berasal dari 1 search engine saja, maka perhitungan skor rangkingnya sebagai berikut:

Doc1 dengan skor similaritas 0.75, 0.56, dan 0.45; Doc2 dengan skor similaritas 0.66 dan 0.22; dan Doc3 memiliki skor similaritas 0.67. Hasil skor similaritas akhir dihitung sebagai berikut: penjumlahan skor similaritas * banyaknya mesin pencari. Sehingga menghasilkan: Doc1 = $(0.75+0.56+0.45) * 3=5.28 ; \quad$ Doc $2=$ $(0.66+0.22) * 2=1.76 ;$ dan Doc3 $=0.67 * 1=0.67$. Dokumen akan dirangkingkan menurut skor similaritas terakhirnya.

\section{B. Metode Kinerja Rata-rata (Interleave)}

Hasil-hasil pencarian web diurutkan menurut kinerja search engine. Sebagai contoh jika search engine $\mathrm{X}$ mencapai rata-rata kinerja lebih tinggi dibandingkan search engine $\mathrm{Y}$ maka dokumen dari X harus diletakkan lebih dahulu daripada dokumen dari Y.

1. Kinerja Kombinasi 2 Search Engine

Hasil perhitungan Mohamed (2004) atas 10 presisi pertama:

- Google-AltaVista: GSF dan fungsi rank similarity lebih baik dari fungsi interleave. Dimana GSF berkinerja lebih baik pada panjang query term $=2$, dan menunjukkan kinerja yang sama dengan rank similarity pada panjang query term $=3$.

- Google-Fast: Fungsi rank similarity berkinerja lebih baik daripada fungsi interleave yang bekerja lebih baik dibandingkan GSF.

- AltaVista-Fast: GSF berkinerja lebih baik daripada fungsi interleave yang lebih baik daripada rank similarity.

\section{Kinerja Kombinasi 3 Search Engine}

Pada 10 presisi pertama: GSF berkinerja lebih baik dari fungsi rank similarity yang berkinerja lebih baik dari fungsi interleave. 
Tabel 3. Ringkasan Hasil Berbagai Kombinasi

\begin{tabular}{|l|l|}
\hline \multicolumn{1}{|c|}{ Kombinasi } & \multicolumn{1}{c|}{ Pemenang } \\
\hline Google - AltaVista & Global Similarity \\
Google - Fast & Rank Similarity \\
AltaVista - Fast & Global Similarity \\
Google - AltaVista - Fast & Global Similarity \\
\hline
\end{tabular}

Secara umum untuk kombinasi 2 dan 3 search engine Global Similarity menjadi pemenang, dan rank similarity menempati posisi ke dua, dan interleave di urutan ke tiga.

\section{HASIL DAN PEMBAHASAN}

\section{A. Kinerja penggabungan 2 search engine}

Untuk membandingkan kinerja dari ketiga metode penggabungan dalam kombinasi 2 search engine, setiap metode penggabungan digunakan untuk mengurutkan ketiga kombinasi yang mungkin dari kombinasi 2 search engine, lalu ratarata skor relevansi digunakan untuk menormalisasi skor-skor rangking. Contohnya dengan mengukur 10 dokumen pertama dalam rangking menurut setiap metode.

\section{B. Kinerja Penggabungan 3 Search Engine}

Setiap fungsi penyatuan digunakan untuk mengurutkan hasil kombinasi untuk ketiga search engine, lalu rata-rata kinerja dari ketiga fungsi penyatuan untuk ke-15 dokumen pertama digunakan untuk membandingkan kinerja fungsi penyatuan.

Baik untuk penggabungan 2 search engine maupun tiga search engine, dilakukan pengujian apakah terdapat perbedaan signifikan terhadap 3 fungsi penyatuan (interleave, rank similarity, dan GSF), kemudian pengaruh panjang query pada fungsi penyatuan, dan pengujian interaksi apakah presisi relatif dari fungsi penyatuan bergantung pada banyaknya query term. Semuanya dilakukan melalui uji 2-way ANOVA.

Sebagai kesimpulan, rata-rata kinerja fungsi penyatuan menunjukkan bahwa GSF bekerja lebih baik daripada 2 fungsi lainnya dalam hal skor penggabungan untuk kombinasi 2 dan 3 search engine.

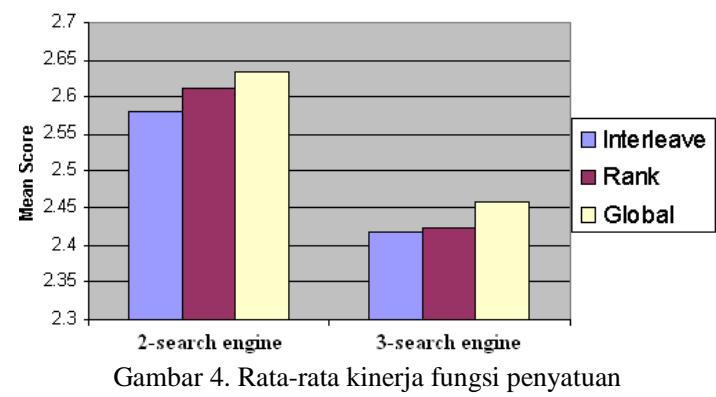

\section{KESIMPULAN}

Makalah ini membahas proses fusi data bagi pengembang meta-search engine yang meliputi: rangking database, kombinasi hasil, dan penggabungan hasil, dengan mempekerjakan 40 query. Pengguna sebenarnya dilibatkan dalam proses penilaian relevansi menggunakan 5 skala relevansi untuk mengevaluasi dan merangking halaman web yang ditarik. Tiga fungsi perangkingan (interleave, rank similarity, dan GSF) telah diajukan untuk mengidentifikasi urutan rangking mana yang terbaik sebagai hasil dari proses penggabungan.

Ada 3 hipotesis yang dirancang untuk membentuk langkah-langkah utama dari proses pembangunan meta-search. Hipotesis pertama mengasumsikan bahwa search engine yang lebih besar cenderung menarik lebih banyak dokumen yang relevan dibandingkan search engine yang lebih kecil. Hasil penelitian menunjukkan tidak selalu search engine yang lebih besar menarik dokumen-dokumen yang lebih relevan. Semua harus dievaluasi melalui berbagai pengukuran yang dikenal di IR.

Hipotesis ke dua adalah menguji efek berbagai kombinasi menggunakan berbagai metode kombinasi dengan melihat pada rasio presisi. Hasil menunjukkan global similarity function (GSF) berkinerja lebih baik dibandingkan rank similarity 
dan interleave pada kombinasi 2 search engine.

Pada kombinasi 3 search engine GSF juga berkinerja lebih baik daripada 2 fungsi lainnya. GSF menghasilkan rangking yang tinggi untuk dokumen-dokumen yang overlap.

Hipotesis ke tiga menguji pengaruh ketiga fungsi penggabungan pada daftar rangking terakhir. Secara rata-rata GSF berkinerja lebih baik pada kombinasi 2 dan 3 search engine dibandingkan metode-metode lain tetapi tes secara statistik menunjukkan tidak ada perbedaan signifikan di antara ketiga fungsi.

Makalah ini menunjukkan beragam evaluasi kinerja terhadap search engine sebelum ditambahkan ke dalam daftar database. Dokumendokumen yang overlap menambah rasio presisi dari daftar yang digabungkan.

\section{SARAN}

Pertama, diperlukan baseline untuk mengukur recall search engine. Karena recall masih tetap penting khususnya bagi query complex yang basanya menarik sejumlah kecil hits. Cara untuk mengukur recall bergantung pada pencarian dokumen tertentu di antara search engine-search engine, khususnya dokumen-dokumen terbaru yang diposting di web.

Kedua, karena meta-search engine menggabungkan hasil dari berbagai search engine dimana pencarian individual menghasilkan posisi hasil pada sebuah halaman khusus search engine maka dibutuhkan penelitian lebih lanjut jika ingin menghasilkan rangking yang lebih baik untuk hasil yang efektif. Beberapa metode mungkin menggunakan penjumlahan hasil posisi dari berbagai halaman individual search engine, dan atau menggunakan fungsi count untuk menentukan rangking untuk menjamin hasil pencarian efektif hasil pencarian. Patel \& Shah (2012) memberikan contoh dasar algoritma rangking untuk metasearch engine.

Ketiga, pemikiran lain untuk mengclusterkan hasil-hasil pencarian web dari berbagai search engine terlebih dahulu kemudian membuat daftar akhir gabungan algoritma rangking membutuhkan studi tersendiri tentang rangking pada cluster. Sebagai standar emas adalah dibandingkan dengan penilaian relevansi hasil dari open directory search engine (http://www.dmoz.com) yang memiliki tingkat relevansi dokumen yang tinggi.

\section{REFERENSI}

[1] Cyril W Cleverdon, "The Significance of the Cranfield test on index languages," Proceedings of 14th Annual International ACM/SIGIR Conference on Research and Development in Information Retrieval, pp. 3-12, 1991.

[2] J Dong, "Combination of Multiple Web Based Search Result and Its Effect on the Search Performance," University of Illinois, Urbana, PhD dissertation 2000.

[3] E Fox \& J Show, "Combination of Multiple Search," In TREC 2, pp. 243-249, 1994.

[4] A Spink, Saracevic J Jansen, "Real Life, Real Users, and Real Needs: A Study and Analysis of Users Queries on the Web," Information Processing and Management, vol. 2, no. 12, pp. 207-227, 2000.

[5] KAEF Mohamed, "Merging Multiple Search Results Approach For Meta Search Engines," University of Pittsburgh, PhD Thesis 2004.

[6] B Patel \& D Shah, "Rangking Algorithm for Meta Search Engines," International Journal of Advanced Engineering Research and Studies, vol. II, no. I, pp. 39-40, Oct-Dec 2012.

[7] J Lee, "Analysis of Multiple Evidence Combination Annual ACM Conference on Research and Development in Informaion Retrieval," Proceeding of the 23rd Annual International Conference on Research and Development in Information Retrieval, pp. 267-276.

[8] E Sormunen, "Libera Relevance Criteria of TREC Counting on Negligible Documents?," Proceeding of 25th Annual International ACM/SIGIR Conference on Research and Development in Information Retrieval, pp. 324-330, 2002.

[9] B Yuwono \& D L Lee. (1996) Search and Rangking Algorithms for Locating on the World Wide Web. [Online]. http://www.cs.ust.hk/ dlee/

[10] S Lawrence \& Giles CL. (1999) Accesibility of Information on the Web. [Online]. http://www.metrics.com/ 
APPENDIKS 1. Banyaknya dokumen overlap dalam 2 dan 3 engine.

\begin{tabular}{|c|c|c|c|c|c|c|}
\hline Query \# & \# of overlap & $\begin{array}{c}\text { Overlap_in_2 } \\
\text { engines }\end{array}$ & $\begin{array}{c}\text { Overlap_in_3 } \\
\text { engines }\end{array}$ & $\begin{array}{l}\text { Google \& } \\
\text { AltaVista }\end{array}$ & $\begin{array}{l}\text { Google } \\
\text { \& Fast }\end{array}$ & $\begin{array}{c}\text { AltaVista } \\
\text { \& Fast }\end{array}$ \\
\hline 1 & 7 & 7 & 0 & 6 & 0 & 1 \\
\hline 2 & 3 & 3 & 0 & 1 & 1 & 1 \\
\hline 3 & 5 & 3 & 2 & 1 & 0 & 2 \\
\hline 4 & 2 & 2 & 0 & 1 & 0 & 1 \\
\hline 5 & 10 & 6 & 4 & 3 & 2 & 1 \\
\hline 6 & 8 & 2 & 6 & 1 & 1 & 0 \\
\hline 7 & 5 & 5 & 0 & 2 & 0 & 3 \\
\hline 8 & 3 & 2 & 1 & 1 & 0 & 1 \\
\hline 9 & 4 & 4 & 0 & 2 & 0 & 2 \\
\hline 10 & 2 & 2 & 0 & 0 & 1 & 1 \\
\hline 11 & 3 & 3 & 0 & 0 & 1 & 2 \\
\hline 12 & 7 & 6 & 1 & 4 & 0 & 2 \\
\hline 13 & 7 & 4 & 3 & 0 & 3 & 1 \\
\hline 14 & 2 & 2 & 0 & 1 & 0 & 1 \\
\hline 15 & 7 & 5 & 2 & 1 & 0 & 4 \\
\hline 16 & 10 & 10 & 0 & 5 & 4 & 1 \\
\hline 17 & 3 & 3 & 0 & 3 & 0 & 0 \\
\hline 18 & 5 & 3 & 2 & 1 & 0 & 2 \\
\hline 19 & 2 & 2 & 0 & 1 & 1 & 0 \\
\hline 20 & 5 & 4 & 1 & 0 & 1 & 3 \\
\hline 21 & 2 & 2 & 0 & 0 & 0 & 2 \\
\hline 22 & 4 & 3 & 1 & 1 & 0 & 2 \\
\hline 23 & 8 & 4 & 4 & 2 & 1 & 1 \\
\hline 24 & 7 & 6 & 1 & 5 & 0 & 2 \\
\hline 25 & 4 & 1 & 3 & 0 & 1 & 0 \\
\hline 26 & 5 & 4 & 1 & 2 & 1 & 1 \\
\hline 27 & 6 & 4 & 2 & 1 & 0 & 3 \\
\hline 28 & 7 & 3 & 4 & 1 & 0 & 2 \\
\hline 29 & 1 & 1 & 0 & 0 & 0 & 1 \\
\hline 30 & 7 & 7 & 0 & 2 & 2 & 3 \\
\hline 31 & 5 & 4 & 1 & 3 & 0 & 1 \\
\hline 32 & 3 & 3 & 0 & 1 & 1 & 1 \\
\hline 33 & 3 & 3 & 0 & 2 & 0 & 1 \\
\hline 34 & 3 & 2 & 1 & 0 & 1 & 1 \\
\hline 35 & 6 & 3 & 3 & 1 & 1 & 1 \\
\hline 36 & 5 & 4 & 1 & 2 & 2 & 0 \\
\hline 37 & 3 & 3 & 0 & 2 & 0 & 1 \\
\hline 38 & 3 & 3 & 0 & 2 & 0 & 1 \\
\hline 39 & 6 & 5 & 1 & 2 & 2 & 1 \\
\hline 40 & 0 & 0 & 0 & 0 & 0 & 0 \\
\hline Sum $=820$ & 188 & 143 & 45 & 63 & 27 & \\
\hline $19.50 \%$ & $12 \%$ & $7.50 \%$ & $44.10 \%$ & $18.20 \%$ & $37.70 \%$ & \\
\hline Whole_set & 5.85 & 3.6 & 1.125 & 0.65 & 0.675 & 1.35 \\
\hline Two_term_length & 5 & 3.9 & 1.1 & 1.7 & 0.75 & 1.45 \\
\hline Three_term length & 4.4 & 3.25 & 1.15 & 1.45 & 0.6 & 1.25 \\
\hline
\end{tabular}

